\title{
Iranian EFL Learners' Attitudes Towards the Use of Computer-mediated PowerPoint Presentations
}

\author{
Omid Tabatabaei \\ English Department, Najafabad Branch, Islamic Azad University, Najafabad, Iran \\ Email: tabatabaeiomid@yahoo.com \\ Maryam Makaber Bandari \\ English Department, Najafabad Branch, Islamic Azad University, Najafabad, Iran
}

\begin{abstract}
The application of educational technology, especially in EFL learning and teaching, has remarkably increased. Although many previous studies have been done on the effect of educational technology on learners' performance, a few of them investigated MA Iranian students' attitudes towards PowerPoint presentation. Therefore, an attempt has been made in the current study to determine MA students' attitudes towards the effect of PowerPoint presentations on their course-related behaviors and elicit the participants' evaluating the effectiveness of their instructor's performance in the PowerPoint classes in comparison with the traditional ones. Sixty MA freshmen TEFL students' perceptions were investigated through 2 sets of questionnaires, as well as 10 sessions of class observation. The analysis of the results revealed that although PowerPoint presentation had positive effect on the learners' class discussions and weblog usage, it did not enhance the students' class attendance and note taking. The learners rated their instructor's performance above average in the traditional classes, while they evaluated the teacher in the PowerPoint class average. The findings of this study can assist decision-makers to explore the merits and demerits of applying PowerPoint in classes according to the participants' perceptions.
\end{abstract}

Index Terms - attitudes, CALL, educational technology, PowerPoint presentation, traditional class

\section{INTRODUCTION}

In the last decade, the usage of technology in higher education, especially in the field of foreign language learning and teaching, has become remarkably widespread (Conner \& Wong, 2004). PowerPoint (PP) is one of the media created in 1987 mainly for the preparation of business slides (Nouri \& Shahid, 2008). The presentations were only linear and were always proceeding from one slide to the next, but PP has gone through dramatic changes and gained prominence in presenting visual information along with lectures. Today PP has the capacity to integrate graphics, sounds, animations and so on; therefore, it has become suitable for education and has quickly penetrated the higher educational settings. Apparently, this way of transmitting information has revolutionized the traditional chalk and blackboard, and maybe non-effective, educational methods. Although the content of the lesson stays the same, the materials are presented differently.

Like other technologies, PP has its own proponents and opponents. Supporters of this educational technology believe that the application of PP enhances students' learning; they also claim that due to shortage of time in presenting course materials, more materials can be covered in one session. While, on the other hand, opponents argue that using PP diminishes students' creativity and innovation (Tufte, 2003). They claim that reducing complex issues to bulleted points is detrimental to students' learning process. In other words, because the amount of information in the presentation must be condensed, viewing a PP presentation does not give students enough detailed information; thus, it is more difficult to see logical relationships between different sets of the data (Simon, 2005). Nowadays, PP has become popular and almost every university allocates rooms equipped with a computer and data projector to present the course data allowing teachers to benefit from a variety of materials, examples, and methods in their lessons.

Since learners are involved in learning and using PP as an educational technology and are exposed to its advantages and disadvantages, there is a need to survey and to consider their attitudes and ideas towards PP use. Personal attitudes are a major factor to affect individual use of educational technology. It is strongly believed that attitudes play a crucial role in academic achievements. They are the hypothetical constructs that represent an individual's degree of like or dislike of something. It is generally accepted that positive attitude can have crucial and a very positive effect on learning by enhancing students' motivation and leading them to achieve educational goals, while, on the other hand, negative one adversely affects learning. The negative attitude usually exerts a detrimental effect on students' motivation and learning.

Supplying universities with computers and PP software does not necessarily mean that educational goals are accomplished by integrating this technology into higher educational curriculum. Many studies have reported failure in incorporating this technology into an educational environment (e.g., Dooley, 1999; Eteokleous, 2008; Keengue \& 
Onchwari, 2008 as cited in Paradi, 2010). These studies show that only making this technology available to the teachers and introducing it to the educational environment are not sufficient to achieve educational goals; therefore, the effective integration of technology into educational instruction is a very crucial issue. Serving this purpose, it is an essential value to determine students' perceptions. If they perceive PP as an efficient and beneficial technology, the integration will be achieved much more easily. Hence, successful implementation depends upon students' having a positive perception towards it.

When teachers, students and administrating officials are not completely aware of how to use a new technology and how to combine it with other methods and technologies effectively in higher educational settings, consequently, it would lead to the emergence of different problems for those who are being involved in teaching and learning process.

\section{BACKGROUND}

There are many definitions of the term "attitude". The researcher adopted the following definition of the term "attitude" as it is convenient to the context of the present study, "the positive or negative changes that may happen in MA TEFL students towards the application of the multimedia in their English classes". (Glazewski, Newby, \& Ottenebeit, 2010, p. 1325). When students use an exciting curriculum with high motivation, the curriculum will improve their learning. Their motivation and satisfaction in using the technology is embedded in their perceptions and attitudes toward it. Simpson et al. (1994, p.47) noted that "the key to success in education often depends on how a student feels toward home, self, and school." Attitudes towards learning and teaching language have been found significant in predicting success in the learning or acquisition process. The educational technology a student receives can be a determining factor of satisfaction. So, researchers have given much attention to attitudes because of the relationship between attitudes and other variables, such as academic achievement. Ajzen and Fishbein (1980) stated the most important reason for studying attitudes in the relationship of attitude to behavior. The behavior a student exhibits during a learning process can be associated with student's satisfaction of a course (Arbaugh, 2000).

Over the last ten years, many scholars have done research on the issues of technologies and their applications in educational setting especially in high educational environment. Some of them were interested in examining and evaluating PP presentations in comparison with TR ones in different areas of language learning and teaching. These researches have investigated, discussed and elaborated different aspects of this prevalent multimedia, i.e., PP, but a few of them have focused on learners' perceptions regarding PP usage in the classroom. In the study conducted by Nouri and Shahid (2008), the researchers' purposes were to explore whether providing lecture notes when PP is used for class presentation affects accounting students' performance and attitudes towards the instructor. This study argued that writing the notes in class rather than providing them to students before the class can have positive effect on students' attitudes and performance. Students' scores on their exams were analyzed and the results showed that there were no significant differences in students' exam performance between the control and experimental groups. Regarding students' attitudes, those who are in the class without providing PP notes evaluated the instructor higher just on such attributes as receptiveness to student concern, efficiency, understandability, and effectiveness. The other attributes were not significantly different.

Susskind (2008) performed a study on the effects of accompanying lectures with computer-mediated PP presentations on students' self-efficacy, attitudes, and class-related behaviors, i.e., performance on exams, class attendance, participation in class discussions, and course website usage. Susskind expected that students would be more interested in material with the PP lectures; this in turn, should enhance their motivation and these motivated students have higher self-efficacy and display better performance on the exams. The results showed that the students displayed a clear preference for lectures accompanied by PP presentations even though the lecture content was the same. They believed these lectures were more organized, more interesting and enjoyable. Further, they reported that the professor did a better job with PP presentation. Students were more motivated to attend those classes. Regarding the students' performance, no effects of teaching format on the students' performance were observed. Considering the website usage, although both classes had access to the same course website, students who saw computer mediated-presentations viewed the website content as more interesting and useful. The students also had stronger academic self-efficacy beliefs when PP presentations were employed. Susskind reported that although the participants claimed they were more motivated to attend lectures with PP presentation, the lecture format did not affect attendance.

To investigate the relationships among access to online notes, examination performance and student absenteeism, Christopherson and Grabe (2005) conducted a study in which 170 psychology participants were provided with the opportunity to complete a questionnaire to gather information concerning attendance and descriptions of how often the participants used online notes. Correlations between note access and examination performance were significant, but weak. Students' questionnaire responses indicated that online resources were used as a way to compensate when students missed class. According to Christopherson and Grabe's study, providing lecture notes reduces class attendance.

The effect of online lecture notes availability on the participants' attendance, participation, and exam performance are the objective of Babb and Ross's (2009) study. It was hypothesized that students in classes that had slide available before lectures would show a higher attendance rate compared to students in classes that had slides available only after lectures. The results showed that classes in which slides were posted before lectures had greater satisfaction. These participants claimed that the slides were more thorough than did those who had access to slides only after class. 
Students in the before-lecture class notes had a significantly higher mean proportion of participation than did those in the after-lecture notes available. Students' exam performance was measured applying multiple-choice midterm and final exams. It was noted that the mean exam percentage of the before-lecture class was higher than the after lecture class.

\section{STATEMENT OF THE PROBLEM}

Although several studies such as Rozalind and Muir (2004), Christopherson and Grabe (2005), Nouri and Shahid (2008), Susskind (2008), Salvendy (2009), Savoy (2009), Betson et al. (2010) have been conducted to figure out the pedagogical benefits of PP and to indicate its impact on students' performance, information retention, learning, PP effectiveness in lectures, self-efficacy and the like, it seems that its impact on MA students' attitudes towards the effectiveness of its application have been overlooked.

EFL learners' attitudes would be a key element when it came to take practicing the use of PP in English classes. Therefore, assessing students' attitudes toward this technology is essential. Based on the researcher's knowledge, it seems that the efficiency and the way to apply PP as a supplementary tool is not clear enough for teachers and learners in foreign language teaching and learning process, so its success and effectiveness can be more obviously determined by eliciting learners' attitudes to make them sure about its usefulness and to remind those in charge of learning process the efficiency of such teacher-aided tool in English classes. One way to ensure that instructors are positively influencing the learning environment by using this technology is by asking the students about their opinions regarding the technology use. Otherwise, it may lead to the creation of some demotivating factors for the learners and at the same time waste the teachers' efforts and energy in presenting the course materials and in providing students with the academic skills, and thus wasting the university budget and fund.

Therefore, the main concern of this study is to shed light on the impact of PP presentations (as a higher educational technology in English classes) on the participants' course-related behaviors- i.e., class discussions, class attendance, teacher's personal weblog usage and note-taking- and to elicit the participants' attitudes towards evaluating the effectiveness of the instructor's performance in the PP classes as compared to the TR classes.

\section{RESEARCH QUESTIONS}

Based on the problems and objectives, this study has made an attempt to seek appropriate answers to the following questions:

1. Does the use of computer-mediated PowerPoint presentations affect MA students' attitudes regarding their courserelated behaviors such as participating in class discussions, class attendance, course weblog usage and note-taking?

2. Does the use of computer-mediated PowerPoint presentations influence MA students' attitudes towards the evaluation of their instructor's performance?

\section{RESEARCH HYPOTHESES}

Based on the above mentioned questions, the following hypotheses have been formulated in this study:

H01: Computer-mediated PowerPoint presentation does not have any effect on students' course-related behaviors such as their attendance in the PowerPoint classes, participation in class discussions, note-taking, and using the teacher's personal weblog.

H02: PowerPoint presentation does not have any effect on students' attitudes, who are taught by PowerPoint slides, towards their instructor's performance in PowerPoint classes in comparison with traditional presentations.

\section{METHOD}

\section{A. Participants}

The study was carried out with 60 MA freshmen students, majoring in TEFL, aged 23 to 40 at three Iranian Universities. The participants were taking 2 compulsory courses in the first semester; both were two-credit courses at MA level, namely, Phonology and Research Methodology. The courses were presented once a week for 90 minutes. One of the reasons for selecting the aforementioned courses was that Research Methodology was taught applying PP, while Phonology was not presented taking advantage of PP slides. The other reason was that both courses were taught by the same instructor.

\section{B. Materials}

To achieve the current research goals, 2 sets of questionnaires were distributed among the participants, and 10 classroom observation checklists were filled in during one semester by the researcher.

Reviewing the questionnaires used by Apperson, Laws, and Scepansky, (2006), Nouri and Shahid (2008), Austin and Tang-Ping (2009), Demirci (2009), Babb and Ross (2009), and Betson et al. (2010), two sets of questionnaires were prepared and altered to meet the requirements of the study. Each item was measured on a 5-point Likert scale including strongly disagree (1) to strongly agree (5). At the end of each questionnaire there was some room left for the participants' comments. 
The first questionnaire consisting of 19 items was designed to collect data regarding the participants' course-related behavior attitudes towards using PP in class. The questionnaire also contained 3 open-ended questions concerning the participants' previous experience with PP in order to see whether they already had such an experience in their BA programs; since the extent of such experience may have had an effect on their attitudes, those who answered yes to this question were excluded from the study. The reasons about their attendance in the PP class and their general ideas concerning more desirable items of the PP class in comparison with the TR one were included in the second and third open-ended questions.

The second questionnaire including 18 items was prepared to elicit the participants' overall perceptions and attitudes towards evaluating the effectiveness of their instructor's performance in both classes, TR and PP. In order to elicit students' ideas about a more effective and favorable feature regarding the instructor's performance in the PP class in comparison with the TR one, an open-ended question was designed.

In addition to the questionnaires and in order to explore the participants' course-related behaviors directly in the two classes (PP and TR), 10 sessions of class observation were conducted by the researcher. To this end, the observation checklist was already available and was taken from Nunan (1989) and Ullmann and Geva (1985). Since the researcher intended to determine class attendance and discussions, the checklist was modified to meet the objectives of the research. The observation checklist was filled out by the researcher for both classes.

\section{Procedures}

In order to observe the participants' course-related behaviors (i.e., class discussions and class attendance) directly, ten sessions of observation were conducted by the researcher during one semester. To habituate the participants to observer presence, the observations were conducted from the first session of the courses. To access inter-observer reliability, two other observers also filled out the checklists. The inter-observer reliability was 0.84 , which showed a high inter-observer reliability. For being minimally intrusive, the observers sat in the back of the class, in order not to make the participants distracted by their note taking or gaze.

Since observations could not be considered sufficient for the researcher to have access to all participants' attitudes and ideas, in addition to class observations, two sets of questionnaires were administered to the participants.

Since some items of the questionnaires were taken from Nunan (1989) and Ullmann and Geva (1985) and some others were adapted or designed by the researcher herself, before administrating the questionnaires to the research participants, the two sets of questionnaires were given to 6 competent and experienced English teachers (each questionnaire to three teachers), in order to test and finalize the material, on the one hand, and to make sure of the validity of the questionnaires on the other. The teachers have analyzed the content and found one to one correspondence between the content and purpose of the questions. So, the content validity was confirmed. Their comments and suggestions were also gathered. After reviewing the questionnaires, a pilot study was carried out.

To ascertain the reliability of the questionnaires, the questionnaires were pilot tested with 12 sophomore MA TEFL students at the same 3 universities. They were not supposed to take part in the main phase of the study and already passed the two major courses (i.e., Phonology and Research Methodology). After carrying out the pilot test, necessary revisions were made.

After collecting the data, the reliability indexes for the questionnaires were computed. The Cronbach Alpha was used to estimate their reliability indexes and it was acceptable. The questionnaires reliability were .70 and .82 , respectively.

In the next stage, the main participants were provided with the opportunity to complete the first questionnaire in week 11 of the semester aiming at eliciting their attitudes towards course-related behaviors. Before administrating the questionnaires, the students were informed of how to fill them in; they were asked to write the code number, not their names, so that their identities would remain confidential.

The second set of the learners' questionnaires were administered in the same way in weeks 12 . The timing for administering each questionnaire was about 20 minutes.

\section{DATA ANALYSIS}

\section{A. Results regarding Course-related Behavior Questionnaire}

Research question one focuses on whether PP presentation has effect on students' course-related behaviors. To address this question, the data collected through the first questionnaire analyzed. Table 1 indicates the effect of PP presentations on the students' class attendance which was concluded based on the learners' answers to the second openended question on the same questionnaire.

TABLE 1

THE IMPACT OF PP PRESENTATIONS ON LEARNERS' CLASS ATTENDANCE

\begin{tabular}{|l|l|l|}
\hline Items & Frequency & Percent \\
\hline Enthusiasm & 32 & $53.3 \%$ \\
\hline course regulations & 15 & $25 \%$ \\
\hline enthusiasm and course regulations & 3 & $5 \%$ \\
\hline No answer & 10 & $16.6 \%$ \\
\hline
\end{tabular}


As the table indicates, the majority of the students $(53.3 \%)$ claimed that they attended PP classes because of their enthusiasm and the terrible feeling caused by missing these classes. They noted that lots of problems could be solved by teachers in the PP classes and they did not want to lose discussions in such classes. Twenty five percent of the participants, mostly males, attended PP class due to the course regulations, 5\% of the participants attended PP classes because of both enthusiasm and course regulations. About sixteen percent of them did not answer this question. Table 2 presents the results considering the third open-ended question, focusing on more desirable item in the PP classes in comparison with the TR ones.

TABLE 2

DESIRABLE ITEMS IN PP CLASSES

\begin{tabular}{|l|l|l|}
\hline Desirable Items & Frequency & Percent \\
\hline attention-capturing & 15 & $25 \%$ \\
\hline organized content & 8 & $13.3 \%$ \\
\hline passive note taking & 12 & $20 \%$ \\
\hline better presentations & 7 & $11.6 \%$ \\
\hline discussion-centered & 15 & $25 \%$ \\
\hline
\end{tabular}

As Table 2 represents, $25 \%$ of the students stated that PP classes were more interesting and attention capturing than TR ones. About $13 \%$ mentioned that the course content was more organized and easier to follow by PP slides. Another $20 \%$ believed that they were not engaged in taking notes. Saving time and better presentations were among the other desirable items in the PP classes which were held by about $11 \%$, and finally, discussion-centered class was the other desirable feature of PP which accounted for $25 \%$ of the learners choices.

To address this question, the data have been collected through the first questionnaire were subjected to Chi-square test for each item. Table 3 summarizes the data analyzed through Chi-square test.

TABLE 3

THE Results OF CHI-SQuARE TEST FOR COURSE-RELATED BEHAVIOR QUESTIONNAIRE

\begin{tabular}{|l|l|l|l|l|}
\hline NO & Item & $\chi^{2}$ & df & Sig. \\
\hline 1 & information retention & 32.333 & 4 & .000 \\
\hline 2 & staying focused & 32.667 & 4 & .000 \\
\hline 3 & enthusiasm maintenance & 24.833 & 4 & .000 \\
\hline 4 & structured lectures & 47.167 & 4 & .000 \\
\hline 5 & being motivated & 24.500 & 4 & .000 \\
\hline 6 & following presentations & 42.833 & 4 & .000 \\
\hline 7 & useful notes & 20.167 & 4 & .000 \\
\hline 8 & organized notes & 34.833 & 4 & .000 \\
\hline 9 & passive discussion & 8.333 & 4 & .080 \\
\hline 10 & less interaction & 8.833 & 4 & .065 \\
\hline 11 & asking questions & 24.167 & 4 & .000 \\
\hline 12 & boring class & 14.167 & 4 & .007 \\
\hline 13 & active students & 16.333 & 4 & .003 \\
\hline 14 & instructor-centered & 20.500 & 4 & .000 \\
\hline 15 & unwilling attendance & 3.833 & 4 & .429 \\
\hline 16 & enhancement of note posting & 34.833 & 4 & .000 \\
\hline 17 & weblog & 35.167 & 4 & .000 \\
\hline 18 & getting access to complete text & 8.500 & 4 & .075 \\
\hline 19 & time consuming download & 2.667 & 4 & .615 \\
\hline
\end{tabular}

As it is shown in Table 3, the results confirm that the students have positive attitudes towards most of the items mentioned in the questionnaire; therefore, PP presentations have a positive effect on the learners. According to the data in Table 4.3, the participants expressed that PP helped them to retain information more $\left(\chi^{2}(4, \mathrm{n}=60)=32.333, p=.000\right)$, it was easy to stay more focused on the lectures $\left(\chi^{2}(4, \mathrm{n}=60)=32.667, p=.000\right)$, and their enthusiasm was maintained more in such classes $\left(\chi^{2}(4, \mathrm{n}=60)=24.833, p=.000\right)$. They cited that lectures were better structured $\left(\chi^{2}(4, \mathrm{n}=60)\right.$ $=47.167, p=.000)$, and they were more motivated to be the audience of PP classes $\left(\chi^{2}(4, \mathrm{n}=60)=24.500, p=.000\right)$. Slides helped them follow the presentations more easily $\left(\chi^{2}(4, \mathrm{n}=60)=42.833, p=.000\right)$. The participants claimed that due to taking complete, useful and more organized notes in the PP classes, they only relied on their notes taken in these classes to be prepared for the test $\left(\chi^{2}(4, \mathrm{n}=60)=34.833, p=.000\right)$. They believed that they were more active to answer the teacher's questions $\left(\chi^{2}(4, \mathrm{n}=60)=16.333, p=.003\right)$, PP classes were more student-centered $\left(\chi^{2}(4, \mathrm{n}=60)=20.500\right.$, $p=.000)$, discussions in such classes were not boring $\left(\chi^{2}(4, \mathrm{n}=60)=14.167, \mathrm{p}=.007\right)$, and slides helped them to ask more questions about the content of the materials $\left(\chi^{2}(4, \mathrm{n}=60)=24.164, p=.000\right)$. The learners felt that using the teachers' personal weblog helped them to reinforce their understanding of the course $\left(\chi^{2}(4, \mathrm{n}=60)=35.167, p=.000\right)$ and posting the slides presented in the class on the teacher's weblog enhanced their learning $\left(\chi^{2}(4, \mathrm{n}=60)=34.833, p=.000\right)$. According to all data analyses, therefore, the first research hypothesis is confirmed. To sum up, PowerPoint presentations have positive effect on the students' attitudes in accordance with their class attendance, class discussions and the usage of the teacher's personal weblog in comparison with the TR classes. 


\section{B. Results regarding Instructor's Performance Evaluation Questionnaire}

The second questionnaire included an open-end question asking the participants about more desirable feature of the teacher's performance in the PP classes. Table 4 shows the descriptive data.

TABLE 4

DESIRABLE FEATURES OF THE INSTRUCTOR'S PERFORMANCE IN THE PP CLASSES

\begin{tabular}{|l|l|l|}
\hline Items & Frequency & Percent \\
\hline main points presentation & 7 & $11.6 \%$ \\
\hline organized teaching & 12 & $20 \%$ \\
\hline learners attraction & 6 & $10 \%$ \\
\hline discussion engagement & 20 & $33.3 \%$ \\
\hline passive note taking & 12 & $20 \%$ \\
\hline too quickly presentations & 3 & $5 \%$ \\
\hline
\end{tabular}

Regarding an open-end question and according to the table briefs, $11.6 \%$ of the participants tended to express that due to enough time for organizing the materials, the teacher presented main points and objectives of the lesson clearly, her teaching was organized and due to the sequence of the slides, she did not jump from one topic to another (20\%). The learners stated that the instructor attracts learners more in the PP classes (10\%). A good number of the participants (33.3\%) cited that the teacher engaged them in the class discussions more by providing more required examples. Twenty percent of the students believed that they were not worried about taking notes due to posting prepared slides through the teacher's weblog. Only a few students, about $5 \%$, had negative attitudes towards teacher's performance in the PP classes; they claimed that slides were presented too quickly for note taking, and occasionally the instructor skipped some slides.

Participants were asked to evaluate the effectiveness of the instructor's performance in the PP class through research question two. To address this question, the answers provided by the participants to the second questionnaire were considered by conducting Chi-Square test. Table 5 tabulates the data for instructor's performance questionnaire.

TABLE 5

CHI-SQUARE TEST FOR INSTRUCTOR'S PERFORMANCE QUESTIONNAIRE

\begin{tabular}{|l|l|l|l|l|}
\hline NO & Item & $\chi^{2}$ & df & Sig. \\
\hline 1 & mastery & 15.167 & 4 & .004 \\
\hline 2 & keeping interest & 30.500 & 4 & .000 \\
\hline 3 & time management & 4.667 & 4 & .323 \\
\hline 4 & skills application & 19.167 & 4 & .001 \\
\hline 5 & problem solving-critical thinking & 7.167 & 4 & .127 \\
\hline 6 & clarifying objectives & 12.833 & 4 & .012 \\
\hline 7 & explanation of problems & 16.833 & 4 & .002 \\
\hline 8 & eye-contact & 12.667 & 4 & .013 \\
\hline 9 & examples and exercises & 12.500 & 4 & .014 \\
\hline 10 & input solicitation & 29.167 & 4 & .000 \\
\hline 11 & instructor's presentation & 5.500 & 4 & .240 \\
\hline 12 & being engaged & 8.833 & 4 & 065. \\
\hline 13 & non-lecture activities & 8.500 & 4 & .075 \\
\hline 14 & occasional use of board & 8.167 & 4 & .086 \\
\hline 15 & fast coverage of slids & 19.500 & 4 & .001 \\
\hline 16 & out of class activities & 11.833 & 4 & .019 \\
\hline 17 & rate of performance in PP & 34.500 & 4 & .000 \\
\hline 18 & rate of performance in TR & 29.667 & 4 & .000 \\
\hline
\end{tabular}

As it can be seen in the table 5, the responses to this questionnaire varied considerably. Students mentioned that the instructor's mastery of subject was more thorough in the PP class $\left(\chi^{2}(4, \mathrm{n}=60)=15.167, p=.004\right)$, and she was more effective in keeping the students interested $\left(\chi^{2}(4, \mathrm{n}=60)=30.500, p=.000\right)$. The instructor offered more opportunities to apply learned skills through exercises and projects $\left(\chi^{2}(4, \mathrm{n}=60)=19.167, p=.001\right)$, she presented the objectives of the course more clearly than in TR classes $\left(\chi^{2}(4, \mathrm{n}=60)=12.833, p=.012\right)$. The teacher engaged audience through her eye contact $\left(\chi^{2}(4, \mathrm{n}=60)=12.667, p=.003\right)$ more in the PP classes. The instructor used more examples and out-of-class activities, explained more about students' problems and elicited students' input more $\left(\chi^{2}(4, \mathrm{n}=60)=12.500, p=.014\right)$ in the PP class. In spite of all the aforementioned items, students reported that the instructor went through the materials too fast to explain all main points $\left(\chi^{2}(4, \mathrm{n}=60)=19.500, p=.001\right)$. Learners were asked to rate their instructor's performance in both classes overly. Both answers were significant $\left(\chi^{2}(4, \mathrm{n}=60)=34.500, p=.000\right.$ for PP classes and $\chi^{2}(4, \mathrm{n}=60)$ $=29.667, p=.000$ ) for TR class). However, they believed that their instructor's performance was above average in the TR classes while it was average in the PP ones. According to all these analyses it was concluded that despite all mentioned positive attitudes towards instructor's performance in PP classes, the learners claimed that the instructor's performance was better in the TR classes, so the second null hypothesis was confirmed i.e., PowerPoint presentation did not have effect on participants attitudes towards instructor's performance.

C. Observation Checklists Analysis 
In order to analyze the data gathered through observation checklists, independent sample $t$-test was run to find the differences between traditional and PP classes. Table 6 indicates the descriptive statistics and Table 7 shows the results of independent sample $t$-test.

TABLE 6

DESCRIPTIVE STATISTICS FOR OBSERVATION CHECKLISTS

\begin{tabular}{|l|l|l|l|l|l|}
\multicolumn{6}{|c}{ DESCRIPTIVE STATISTICS FOR OBSERVATION CHECKLISTS } \\
\hline \multirow{2}{*}{ Items } & $\begin{array}{l}\text { Class } \\
\text { type }\end{array}$ & $\mathrm{N}$ & Mean & SD & $\begin{array}{l}\text { Std. error } \\
\text { Mean }\end{array}$ \\
\hline \multirow{2}{*}{ q for clarification } & PP & 30 & 5.40 & 4.222 & 1.335 \\
& TR & 30 & 6.70 & 4.762 & 1.506 \\
\hline \multirow{2}{*}{ adequate response } & PP & 30 & 3.80 & 2.30 & .727 \\
& TR & 30 & 2.80 & 1.874 & .593 \\
\hline \multirow{2}{*}{ inadequate response } & PP & 30 & 2.50 & 1.179 & .373 \\
& TR & 30 & 1.40 & .699 & .221 \\
\hline \multirow{2}{*}{ students' attention } & PP & 30 & 2.40 & 1.647 & .521 \\
& TR & 30 & 1.90 & .876 & .277 \\
\hline talking instead of & PP & 30 & 2.00 & 1.826 & .577 \\
listening & TR & 30 & 2.60 & 1.647 & .521 \\
\hline \multirow{2}{*}{ Participation } & PP & 30 & 2.20 & 1.549 & .490 \\
& TR & 30 & 2.40 & 1.506 & .476 \\
\hline \multirow{2}{*}{ active involvement } & PP & 30 & 1.60 & 1.265 & .400 \\
& TR & 30 & 2.20 & 1.135 & .359 \\
\hline \multirow{2}{*}{ Interaction } & PP & 30 & .40 & .516 & .163 \\
& TR & 30 & 1.00 & 1.491 & .471 \\
\hline \multirow{2}{*}{ note taking } & PP & 30 & 2.60 & 1.647 & .521 \\
\hline \multirow{2}{*}{ use of whiteboard } & TR & 30 & 5.10 & 1.449 & .458 \\
\hline & PP & 30 & 1.60 & 1.075 & .340 \\
& TR & 30 & 6.70 & 3.268 & 1.033 \\
\hline
\end{tabular}

TABLE 7

INDEPENDENT SAMPLES T-TEST FOR PP AND TR CLASSES

\begin{tabular}{|l|l|l|l|l|}
\hline Case & $\mathrm{t}$ & $\mathrm{df}$ & Sig. & Mean diff. \\
\hline Question for clarification & -.646 & 18 & .526 & -1.30 \\
\hline Adequate response & 1.066 & 18 & .301 & 1.00 \\
\hline Inadequate response & 2.538 & 18 & .021 & 1.10 \\
\hline Students' attention & .848 & 18 & .408 & .50 \\
\hline Talking instead listening & -.772 & 18 & .450 & -.60 \\
\hline Participation & -.293 & 18 & .773 & -.20 \\
\hline Active involvement & -1.116 & 18 & .279 & -.60 \\
\hline Interaction & -1.203 & 18 & .254 & -.60 \\
\hline Note-taking & -3.604 & 18 & .002 & -2.50 \\
\hline Use of whiteboard & -4.688 & 18 & .000 & -5.10 \\
\hline
\end{tabular}

Among all 10 items, significant differences were found for taking notes, using the whiteboard and responding inadequately to the teacher's questions between the two classes. As Table 7 represents, the difference between the two types of presentation (that is, PP and TR) regarding inadequate responses were significant $(t=2.538, p=.000)$. By considering the obtained means which were indicated in Table 6 above (2.50 for PP versus 1.40 for traditional class) it is concluded that although the answers to the teacher's questions were inappropriate and inadequate, the learners were more active to answer the instructor's questions and were more involved in class discussions in the PP class.

The second item which was significant for the two classes (that is, PP and TR) $(t=-3.604, p=.002)$ is related to students' note taking which, according to the obtained means (2.60 for PP class and 5.10 for TR one), showed that the students were more engaged in note-taking in TR classes, and also according to the course-related behaviors questionnaire analysis, learners claimed that their notes were more organized and more complete in PP classes; therefore, there was no need to take notes in such classes.

Finally, the last significant item $(t=-4.688, p=.000)$ is related to teacher's using whiteboard which, according to the obtained means (for PP class 1.60 and for TR 6.70), was more in the TR class.

\section{DISCUSSION}

The analyses of the learners' course-related behavior questionnaire, designed in order to answer the first research question, reveals that computer-mediated PP presentation has positive effects on MA students' class discussions and teacher's weblog usage. Although PP presentation enhances the aforementioned behaviors, it does not affect the learners' class attendance and note taking. The results also indicates the participants' positive attitudes towards some desirable features of the PP classes such as attention capturing, discussion-centeredness, and more organized presentations.

The findings of this study are in contrast with Nouri and Shahid's (2008) study. Although students in their study viewed PP presentation as more favorable than TR, had positive attitudes towards it, and reported higher understandability about the course content, according to data analysis of the research no significant differences were 
found. The results of the current study showed that MA students believed this style of presentation was more effective for remembering lecture materials and it enhanced their understandability than TR style. The possible reason for this is maybe due to attention capturing nature of the PP which motivates students to discuss more to answer to teacher's questions in order to remove the ambiguity they encounter in the course content. It seems that discussion-centered feature of PP assists the students' understandability.

The results of Susskind's (2008) study showed that the students displayed a preference for lectures accompanied by PP presentations. The participants believed that those lectures were more organized, more interesting and enjoyable. Students were more motivated to attend those classes. Considering the weblog usage, students who were presented applying computer-mediated presentations viewed the weblog content as more interesting and useful. The results obtained in the current study are in accord with Susskind's study regarding the learners' preference for lectures applying PP, class discussions, and weblog usage enhancement. It seems that the learners are more interested in materials with PP lectures, this in turn, should enhance their motivations and these motivated students have positive perceptions towards attending the PP classes, participating in class discussions and accessing the course weblog.

Although the participants claimed they were more motivated to attend lectures with PP presentation (see table 1), their attendance was not affected by the lecture format, and the number of their absences in both classes reveals it; in other words, the number of the participants' absences was identical in both (TR and PP) classes. The main reason for attending class for the participants in the current study can be due to difficult nature of the content of the two mentioned compulsory courses at MA level that they do not want to miss the teachers' clarifications of the courses. The results relating to the learners' class attendance is not consistent with that of the Christopher and Grabe's (2005) study. They reported that when students were provided with the opportunity to use Online Notes, i.e., PP slides were presented to the students posted on the weblog, the students used them as a way to compensate when they missed a class. In their study $79 \%$ of the participants who took the advantage of accessing class weblog and posted PP slides used slides as a replacement for their class attendance.

Concerning the second research question which was meant to find out whether the participants who were presented with PP had positive attitudes towards the instructors' performance, according to the findings of this study, although the learners stated that the teacher engaged them in PP classes more, her/his teaching was more organized, and she/he was more informative, effective, and prepared than in TR classes, they rated the overall performance of their teacher higher and above average in TR classes. This result does not support Susskind's (2008) and Nouri \& Shahid's (2008) study in which professors were evaluated more favorable in PP classes. It seems that above average rating of the instructor's performance in traditional class by the students, was mostly due to instructor's whiteboard usage in providing notes for the participants. It is important to keep in mind that instructor's board use, which is considered as one of the noticeable characters of an active teacher, according to the students' point of view, may influence participants' attitudes towards her performance.

\section{CONCLUSION}

The basic objective underlying the present study was to investigate MA TEFL students' perceptions of computermediated PP use in presenting course materials. This study also sought to figure out whether or not this kind of educational technology presentation affected the learners' class behaviors and the instructors' performance. The findings of this study indicated that MA students tended to express that they were motivated and had positive attitudes towards PP usage in their classes. Their responses to the questionnaire align with analyzing observation checklist confirmed that although applying such technology enhanced the learners' class discussions and teacher's weblog use in order to download the presented slides, PP did not influence their note taking and attendance in the class. Students' taking notes was more in the TR classes than in the PP classes. The rate of their absence was identical in both classes.

With regard to the evaluation of the instructor, in spite of the learners' positive attitudes towards the effectiveness of the instructor's performance in the PP class, they rated the teacher above average in TR class and indicated that she/he was more efficient in the TR presentation.

\section{IMPLICATIONS}

Research findings regarding students' perceptions may have important implications for administrating officials, faculty members, and students. The findings of this study are hoped to be useful for administrating officials and decision-makers at the universities who make effort and spend money to integrate such overwhelming technologies in teaching curriculum to improve the quality of PP classes which are currently used to teach at MA level. Educational decision-makers of the universities are the people who are responsible for improving the use of this technology. It will be more effective if they hold in-service training for the professors who are applying this technology in their classes to improve the quality of such classes. Moreover, the results of this study can help professors to focus on students' perceptions concerning the use of this technology as a training aid tool to enhance students' learning. By eliciting students' attitudes an interaction is built; the interaction with the given technology between the professor and students plays a significant role in learning. This interaction may lead to evaluating the teachers' lesson plans, the software, how it is used, and its impact on students' learning. Regarding the students' attitudes and beliefs, professors can make more 
efficient and more useful slides which are accompanied by sound, diagrams and more examples (specially in Phonology classes) to enhance students learning. In this way, professors are able to maintain students' attention during the lecture. According to the students' comments if handouts and slides are given to them before professor's presentations, due to their familiarity with the topic, it will enhance their class discussions. Depending on the mentioned results, some implications can be given in relation to the learners. Since learners have positive attitudes towards using PP, such attitude can contribute to creating a more attractive, desirable educational environment.

\section{LIMITATIONS}

There are several limitations in the current study which researchers should be aware of. Regarding one of the students' course related behaviors, i.e., note taking, may be posting the slides on the teacher's personal weblog before or after instructor's presentations affect their attitudes towards note taking in both classes.

Another considerable limitation related to students' class discussions, attendance, and note taking, is the nature of the courses (i.e., Phonology and Research Methodology). The difficulty and nature of the two courses may likely to have influence participants' mentioned class behaviors. It is assumed that aforementioned students' course behavior may change in the other compulsory or optional courses.

\section{SUGGESTIONS FOR FURTHER RESEARCH}

The current research focused on determining students' attitudes towards the two different compulsory courses with different natures and difficulties. For future research, investigations can be fulfilled concentrating on one course with different presentations (e.g., presenting Phonology in two classes, both with the same instructor, one with PP as a delivery system and one with using a traditional delivery system). The same course with 2 different ways of presentation for two groups of participants may affect learners' course-related behaviors and their attitudes towards instructor's performance.

The participants in this study were engaged in their note taking and demonstrated their attitudes and effect of PP on their own notes. It is possible to do more research and find the effects of teacher's note; that is, teacher provides his/her own handouts and make them available to the learners either before or after lecture to find out whether this way of note availability affects students' attitudes towards learners' course-related behaviors or not. Other researchers can replicate this study by larger sample sizes to ensure the generalizability of the findings.

\section{REFERENCES}

[1] Ajzen, I., \& Fishbein, M. (1980). Understanding attitudes and predicting social behavior. Englewood Cliffs, NJ: Prentice Hall.

[2] Apperson, J. M., Laws, E. L., \& Scepansky, J. A. (2006). The impact of presentation graphics on students experience in the classroom. Computer and Education, 47(4), 116-126.

[3] Arbaugh, J. B. (2000). Virtual classroom characteristics and student satisfaction with internet-based MBA courses. Journal of Management Education, 24, 32-54.

[4] Austin, M. J., \& Tang Ping, T. (2009). Students' perceptions of teaching technologies, application of technologies and academic performance. Computer and Education, 53(4), 1241-1255.

[5] Babb, A., K., \& Ross, C. (2009).The timing of online lecture slides and its effect on attendance. Computer and Education, 52(4), 868-881.

[6] Beston, R. B., Tangen, M. J., Teeter, C, Constable, D. M., Durrant, E., \& Kim, A. J. (2010). The role of interest and images in slidware presentation. Computer and Education, 56, 865-872.

[7] Christopherson, K., \& Grabe, M. (2005). Evaluating the advantages and disadvantages of providing lecture notes. The Internet and higher Education, 8(4), 291-298.

[8] Conner, M. \& Wong, F. H. (2004). Working through PowerPoint. A global prism for local reflections, Business Communication Quarterly, 67(7), 228-231.

[9] Demirci, A. (2009). How do teachers approach new technology: Geography teachers' attitudes towards Geography information system. European Journal of Education Studies, 1(1), 43-53.

[10] Glazewski, D. K., Newby, J. T., \& Ottenebeit, T. A. (2010). Teachers' value beliefs associated with using technology: Teachers and students need. Computers and Education, 55(3), 1321-1335.

[11] Nunan, D. (1989). Understanding language classrooms: A guide for instructor initiated action. New Jersey: Pearson Education.

[12] Nouri, H., \& Shahid, A. (2005). The effect of PowerPoint presentations on students' learning and attitudes. Global Perspectives on Accounting Education, 2, 53-73.

[13] Nouri, H., \& Shahid, A. (2008). The effect of PP lecture notes on student performance and attitudes. The Accounting Education Journal, 18, 103-117.

[14] Paradi, D. (2010). Ten secrets of using PowerPoint effectively. Retrieved January 21, 2011from http://www.thinkoutslidetheslide.com/articles/ten-secrets-for-using-PowerPoint.htm.

[15] Rozalind, S., \& Muri, H. (2004). Technology and its impact in the classroom. Computer and Education, 42, 111-131

[16] Salvendy, G., Savory, A., \& Proctor, W. R. (2009). Information retention at PP. Computer and Education, 52(4), 858-867.

[17] Savoy, J. (2009). Retrieval effectiveness on the web. Information Processing and Management, 39(4), 581-609.

[18] Simon, T. (2005). Does PP make you stupid? Presentations, 18(3), Retrieved November 21, 2010 from http://g;lobal.factiva.com 
[19] Simpson, R. D., Koballa, T. R., Oliver, J. S., \& Crawley, F. E. (1994). Research on the affective dimension of science learning. In D. L. Grabel (Ed.), Handbook of research on science teaching and learning. New York, NY: Macmillan.

[20] Susskind, E. J. (2008). Limits of PowerPoint: Enhancing students' self efficacy and attitudes but not their behavior. Computer and Education, 50, 1228-1239.

[21] Tufte, E. R. (2003). PowerPoint is Evil. Wired. Retrieved December $8, \quad 2010 \quad$ at http://www.wired.com/wired/archive/11.09/ppt2.html.

[22] Ullmann, R., \& Geva, E. (1985). Expanding our evaluation perspective: What can classroom observation tell us about corn French programs? The Canadian Modern Language Review, 42(2), 319-322. Retrieved at http:// www.utpjornals.com.

Omid Tabatabaei is an assistant professor of TEFL at Islamic Azad University, Najafabad Branch. He is currently the Vice-Dean of Humanities Faculty and the Head of English Department. His areas of interest are: L2 acquisition, Psycholinguistics, and Testing.

Maryam Makaber Bandari holds an M.A in Teaching English as a Foreign Language (TEFL) at Islamic Azad University, Najafabad Branch. She has been an English teacher for 7 years. 